\title{
CVD Prevention Through Policy: a Review of Mass Media, Food/Menu Labeling, Taxation/Subsidies, Built Environment, School Procurement, Worksite Wellness, and Marketing Standards to Improve Diet
}

\author{
Ashkan Afshin ${ }^{1}$. Jose Penalvo ${ }^{1} \cdot$ Liana Del Gobbo $^{1} \cdot$ Michael Kashaf $^{1} \cdot$ Renata Micha $^{1}$ \\ Kurtis Morrish $^{1}$ • Jonathan Pearson-Stuttard ${ }^{2}$ • Colin Rehm ${ }^{1}$ • Siyi Shangguan ${ }^{1}$. \\ Jessica D. Smith ${ }^{1,3}$ • Dariush Mozaffarian ${ }^{1}$
}

Published online: 14 September 2015

(C) The Author(s) 2015. This article is published with open access at Springerlink.com

\begin{abstract}
Poor diet is the leading cause of cardiovascular disease in the USA and globally. Evidence-based policies are crucial to improve diet and population health. We reviewed the effectiveness for a range of policy levers to alter diet and dietrelated risk factors. We identified evidence to support benefits of focused mass media campaigns (especially for fruits, vegetables, salt), food pricing strategies (both subsidies and taxation, with stronger effects at lower income levels), school procurement policies (for increasing healthful or reducing unhealthful choices), and worksite wellness programs (especially when comprehensive and multicomponent). Evidence was inconclusive for food and menu labeling (for consumer or industry behavior) and changes in local built environment (e.g., availability or accessibility of supermarkets, fast food outlets). We found little empiric evidence evaluating marketing
\end{abstract}

This article is part of the Topical Collection on Public Health Policy restrictions, although broad principles and large resources spent on marketing suggest utility. Widespread implementation and evaluation of evidence-based policy strategies, with further research on other strategies with mixed/limited evidence, are essential "population medicine" to reduce health and economic burdens and inequities of diet-related illness worldwide.

Keywords Diet $\cdot$ Policy $\cdot$ Advertising $\cdot$ Tax $\cdot$ Subsidy Schools $\cdot$ Regulation $\cdot$ Worksite $\cdot$ Labeling

\section{Introduction}

Poor diet is the leading cause of cardiovascular disease (CVD), total mortality, and morbidity in the USA and globally
Jonathan Pearson-Stuttard

Jonathan.Pearson-Stuttard@medsci.ox.ac.uk

Colin Rehm

Colin.Rehm@tufts.edu

Siyi Shangguan

Sysgserene@gmail.com

Jessica D. Smith

jesmith@hsph.harvard.edu

Friedman School of Nutrition Science and Policy, Tufts University, 150 Harrison Ave, Boston, MA 02111, USA

Department of Public Health and Policy, University of Liverpool, Liverpool, UK

Department of Nutrition, Harvard T.H. Chan School of Public Health, Boston, MA, USA 
$[1,2]$. Current intakes of major dietary risk factors are suboptimal across the world [3-6]. Clearly, improving dietary habits across populations is a major clinical and policy priority of our time. While individual-level and health care system-based behavioral change efforts can be partly effective [7, 8], policy changes at organizational, community, and government levels can have broader, more equitable, and more sustainable impact $[9 \bullet \bullet$. Because dietary choices are influenced by a range of determinants at individual, sociocultural, community, national, and global levels, potential policy strategies can be applied across a range of different domains (Fig. 1) [10]. To better understand the current evidence for different policy levers, we systematically reviewed the evidence for effectiveness of specific policies to improve dietary habits and reduce cardiovascular and metabolic risk factors.

\section{Methods}

We searched multiple online databases for studies evaluating the effectiveness of policy strategies to improve diet. Specific search terms and strategies are available from the authors upon request. We focused on policies in several domains with prior evidence for effectiveness [9••], including mass media campaigns, food and menu labeling, taxation and subsidies, local built environment, school procurement policies, worksite wellness programs, and marketing standards. For certain domains (e.g., worksite wellness programs), we focused on interventional (randomized, quasi-experimental) studies; for other domains (e.g., taxation and subsidies), we evaluated both interventional and prospective cohort studies. For built environment and studies of price elasticity of demand for food and nonalcoholic beverages, we also included cross-sectional studies given the preponderance of such evidence in these domains.

Our endpoints of interest include changes in dietary habits or diet-related risk factors for cardiovascular disease, in particular adiposity, blood pressure, and blood lipid levels. To provide contemporary evidence, studies were excluded if published prior to 1980 , not reporting effect sizes of the potential intervention of interest, or conducted in special populations having major underlying disease (e.g., metastatic cancer). For final inclusion decisions, all studies were reviewed and evaluated by two investigators independently. For each policy, one investigator took the lead on summarizing the evidence on effectiveness of each policy, with input and guidance from all investigators.

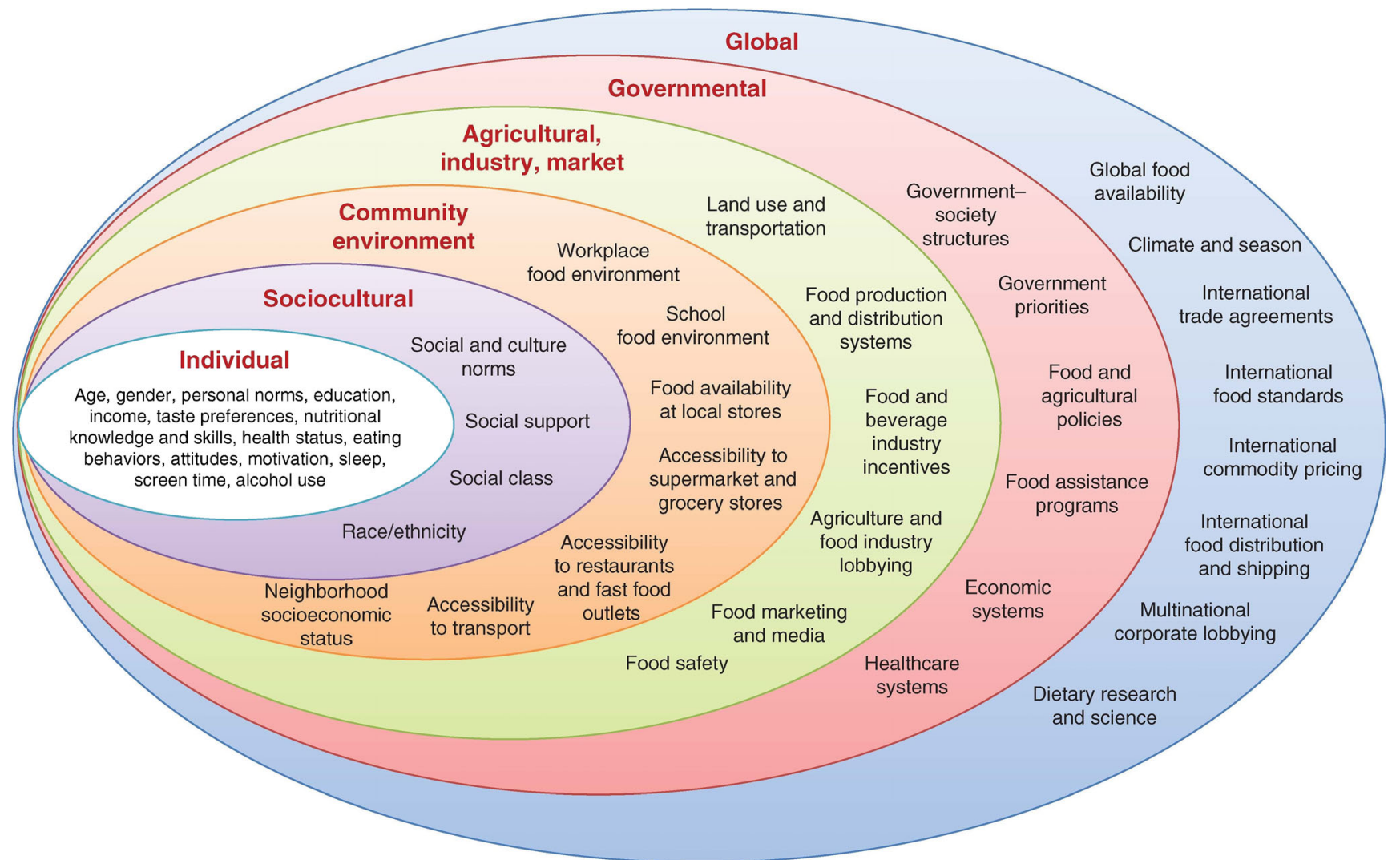

Fig. 1 Barriers and opportunities for healthy eating. (Reproduced with permission from: Afshin A, Micha R, Khatibzadeh S, Schmidt L, Mozaffarian D. Dietary policies to reduce noncommunicable diseases.
In: Brown G, Yamey G, Wamala S, editors. The Handbook of Global Health Policy. Wiley-Blackwell, San Francisco, 2014) [10] 


\section{Results}

\section{Mass Media Campaigns}

Mass media campaigns, either alone or as a part of a multicomponent intervention, provide a tool for the dissemination of evidence-based dietary targets. Over the past three decades, mass media campaigns have been utilized as one feature of successful multicomponent interventions targeting dietary habits at community [11-17] and national levels [18-24]. In such multifaceted interventions, the independent contribution of the mass media component is difficult to evaluate.

Several studies suggest potential effectiveness of mass media campaigns as a stand-alone intervention. These have shown temporal improvements in consumption of specific dietary factors, especially increased fruits and vegetables and (less commonly) reduced salt [25-30]. For example, after implementation of the Australian "2 Fruit ' $n$ ' 5 Veg Every Day" campaign (1992-1994), annual surveys found an increase in intakes of fruits (from 1.5 to 1.7 servings/day; $P<0.05$ ) and vegetables (from 2.6 to 3.1 servings/day; $P<0.001$ ) among adults [25]. This campaign consisted of intensive bursts of TV commercials over a 3-week period in 1992 and 1993 and a 1-week period in 1994, as well as additional print and radio ads. Based on ecologic follow-up over time, the full effect of the campaign was observed during the first year of implementation and sustained, without further increase, in ensuing years [25]. Based on nationally representative crosssectional surveys in 1991 and 1997 following the launch of the US "5-A-Day" campaign in 1991, the proportion of US adults consuming at least 5 servings/day of fruits and vegetables significantly increased; mean national intakes also increased, although this latter finding only remained significant among nonsmokers and Hispanics after adjustment for demographic shifts [31]. Awareness of the health benefits of fruits and vegetables and knowledge of the campaign also increased during this time period [31]. Yet, although the campaign continued through 2007, a relatively low rate of awareness of this campaigns $(29 \%)$ raised concern over full coverage and penetration.

Other mass media interventions in Pakistan (1999-2004) and the USA (1995) used prominent newspaper articles and computer-based newsletters, respectively, to target fruits and vegetables [27, 28]. Of the $75 \%$ of Pakistani readers who read the articles, $40 \%$ reported having changed their dietary behaviors [27]; while in the USA, fruit and vegetable consumption increased (from 3.4 to 4.1 servings per day, $P<0.002$ ) after 6 months of computer-based newsletters [28]. In a metaanalysis of five randomized and nonrandomized interventions from the USA, New Zealand, and Australia, including several of the studies above, implementation of mass media campaigns was associated with 0.25 serving/day increased consumption of fruits and vegetables (95\% CI $=0.15-0.35)$ [29].
In the UK, a national campaign targeting salt intake was associated with a reduced proportion of adults who reported adding salt at the table, from $32.5 \%$ in 2003 to $23.2 \%$ in 2007 [30]. This reduction was consistently observed across age, sex, and socioeconomic groups.

In sum, several studies suggest that a focused mass media campaign, targeting a single dietary factor or related dietary factors, can improve diet. The effectiveness of mass media campaigns on dietary targets beyond fruits, vegetables, or salt is not established. In addition, the quasi-experimental designs of most of these studies suggest but preclude strong conclusions about cause -and- effect of the campaigns. Further investigation is also needed on the influence of varying intensity, penetration, and duration of mass media campaigns, as well as cost-effectiveness and effects on disparities relative to other policy strategies.

\section{Food and Menu Labeling}

Food and menu labeling approaches are widely utilized with the aim to influence consumer choice. These can take several forms including (a) nutrition panels (e.g., Nutrition Facts), (b) nutrient content claims (e.g., "low sodium," "fat-free"), (c) health-related claims, (d) logos based on nutrition criteria (e.g., "green Keyhole" in Sweden [32], "Choices" logo in The Netherlands [33], American Heart Association "HeartCheck" [34]), (e) front-of-pack icons based on a grading system (e.g., "traffic light" icon in UK and Ireland [35, 36], "Guiding Star" program in the USA), [37] and (f) menu labeling (e.g., total calorie content) [38-40].

The effectiveness of food labeling has been evaluated in natural experiments of mandatory food labeling laws over periods from months to more than a year [41-43] and in shorter term randomized and nonrandomized interventions over a meal [44-46] or several weeks [47, 48]. Most studies were conducted in university $[49,50]$, worksite $[47,51,52]$ or community settings $[44,46,53]$ in high-income countries in North America, Europe, or Oceania, and most evaluated populations in which young and middle-aged adults, in particular females, had greater representation. Evaluation of effectiveness has been based on changes in sales [37, 46, 54], selfreported dietary intake $[44,52,53]$, or diet-related risk factors (e.g., BMI) [47, 55].

Overall, these studies have not shown consistent effects on consumer behavior. One preliminary meta-analysis of interventional trials and prospective studies found no significant effect of food and menu labeling on sales or consumption, regardless of label format, dietary target (e.g., calorie content, total fat, dietary fiber), target population, food establishment setting, or mandatory vs. voluntary nature of labeling [56]. The most common dietary targets were energy intake $(n=23$ studies), total fat $(n=8)$, and saturated fat $(n=4)$. Fewer studies have evaluated food labels and diet-related outcomes, such as trans fat concentrations in human breast milk following 
Canada's trans fat labeling regulation [55] and BMI and serum triglycerides in a US worksite intervention incorporating food labeling [47].

While overall effects of food and menu labeling are not clearly identified in populations, concerns have been raised that such interventions, if effective, could potentially exacerbate disparities by having larger effects among higher socioeconomic groups compared with lower socioeconomic groups $[57,58]$. Based on this concern, food labeling should be considered in combination with other intervention such mass media campaigns and education [37, 59], neighborhood environmental change [54], price incentives [52, 60, 61], and quality standards [59] to enhance effectiveness in disadvantaged populations and reduce potential widening of disparities.

Several studies have performed time-series analyses of products to assess the potential impact of food and menu labeling on industry formulations. These reports suggest that menu labeling for sodium in chain restaurants $[62,63]$ and front-of-package supermarket labels [64, 65] may modestly lower sodium contents $[62,64]$. Further studies are needed to confirm the presence and magnitude of this effect as well as evaluate other dietary targets.

\section{Taxation and Subsidies}

Food prices are important determinants of dietary choices [9••, 66]. Proactive strategies can include taxation to reduce intakes of unhealthful foods and subsidies to promote consumption of healthful foods [67]. Evidence on effectiveness of such pricing strategies generally derives from cross-sectional economic models estimating the price elasticity of demand for foods [68, 69•]; and a smaller number of interventional or prospective observational studies evaluating price and consumption changes over time [70].

Cross-sectional demand models demonstrate inverse relationships between price of a given food and its consumption, with magnitudes of elasticity (percent change in consumption per percent change in price) that vary depending on the food as well as a person's country and income level [68, 69•]. For example, based on a systematic review of 160 modeling studies in the USA, price elasticities varied from -0.27 for eggs (i.e., $0.27 \%$ lower consumption per $1 \%$ increase in price) to -0.81 for foods consumed away from home; intermediate values were seen for fish $(-0.50)$, vegetables $(-0.58)$, fruits $(-0.70)$, and soft drinks $(-0.76)[68]$. A systematic review and meta-analysis of 136 studies from 162 countries reported an overall price elasticity of -0.70 for all food groups combined [69•]. This varied by country income, with greater elasticity in low-income countries $(-0.74)$ than in high-income countries $(-0.56)$, and by household socioeconomic status within countries, with greater elasticity in low-income households $(-0.91)$ than in high-income households $(-0.77)$. These crosssectional price elasticity analyses cannot distinguish between potentially varying magnitudes of effects for price increases (e.g., taxation) vs. decreases (e.g., subsides) for the same food.

Prospective observational and interventional studies confirm the effectiveness of pricing strategies to improve diet and also allow direct assessment of increased vs. decreased prices. Based on our own recent review and meta-analysis of such studies, a $10 \%$ price reduction or subsidy increases consumption of healthful foods/beverages by $14 \%$, while a $10 \%$ price increase or tax reduces consumption of unhealthful foods/ beverages by $7 \%$ decrease (unpublished). Our review also suggested that combining pricing strategies with other approaches such as altering food availability enhances the effectiveness of price changes.

Recently, Mexico reported on the changes in consumption of sugar-sweetened beverages (SSBs) 1 year following institution of a one peso per liter (approximately $10 \%$ ) national excise tax that took effect on Jan 1, 2014 (www.insp.mx/ epppo/blog/3659-reduccion-consumo-bebidas.html). Based on a commercial panel of household purchasing data and adjusting for pre-existing trends in SSBs and for other macroeconomic variables, SSB purchasing was reduced by $12 \%$ by December 2014. Effects were evident across all socioeconomic groups, with largest declines (up to $17 \%$ ) in lower socioeconomic households. At the same time, purchases of other, untaxed beverages increased by $4 \%$, mainly due to greater sales of bottled plain water; data on tap water intake was not collected. These quasi-experimental findings, in particular the larger effect among lower socioeconomic individuals, strongly support the efficacy of pricing measures to alter population dietary habits.

\section{Local Food Environment}

Food choices and dietary behaviors are plausibly influenced by an individual's local food environment, e.g., presence and accessibility of supermarkets, grocery stores, convenience stores, fast food restaurants, and full-service restaurants. Availability and accessibility of these outlets have typically been studied by evaluating density (per area or capita) or distance (e.g., to home), with usual outcomes including BMI, other obesityrelated outcomes, or (less commonly) specific dietary components or dietary quality [71]. In addition, some studies have explored in-store availability of foods, walkability to outlets, distance from school or worksites rather than homes, and participation in farmers' markets or community gardens.

Nearly all prior studies of these topics have been crosssectional. In the present review, we identified more than $>150$ relevant cross-sectional studies. Most evaluated multiple neighborhood characteristics, such as outlet density measures or distance from home, in relation to one or more type of food outlet. Overall, these cross-sectional studies observed inverse associations of supermarket availability with adiposity and much more mixed associations for other types of food outlets. 
However, the potential for reverse causation limits strong inference: One cannot determine whether dietary choices are worse in these populations due to absence of supermarkets or whether supermarkets do not succeed in these neighborhoods due to population dietary choices. Moreover, adjustments for individual-level and other neighborhood-level characteristics in some studies were minimal, raising concern for residual confounding from other factors.

Many fewer longitudinal observational or quasi-experimental studies have investigated these questions. Most were USA studies, including in adults [71-75] and children [76-79], with variable sample sizes ( $n=350$ to 28,000 participants) and durations of follow-up (1-30 years). In these prospective studies, findings have been inconsistent, with no clear associations between availability or accessibility of supermarkets or other food outlets and measures of adiposity or diet quality.

In sum, current evidence for effects of the local built food environment on diet or diet-related risk factors remains surprisingly limited. Several challenges are event, including the cross-sectional nature of most studies, the heterogeneity in metrics and definitions used to characterize the local food environment, and the diversity of influences on diet outside the home neighborhood (e.g., other influences at schools or work). Availability of transportation could also be an important effect modifier of associations but has been infrequently evaluated. Further longitudinal investigations, examining diet and diet-related outcomes before and after changes in the local food environment, are needed to better understand how the neighborhood food environment may influence adiposity, dietary quality, and other outcomes.

\section{School Procurement Policies}

Schools can alter dietary choices of their students through procurement policies, such as standards or guidelines for purchasing of foods. We reviewed interventional (randomized or quasi-experimental) studies of school regulation and procurement policies to evaluate their effectiveness on achieving dietary change. We included multicomponent studies if these regulations were a major component of the intervention. Relevant studies were considered across three broad categories: (1) increase in availability of healthful foods and beverages, (2) standards on availability of unhealthful foods and beverages, and (3) implementation of nutrition standards for school meals.

Thirty-one interventions assessed increased availability of healthful foods and beverages, largely in cafeterias or vending machines, with average duration of 8-10 months [80-113]. Most were small-scale, local programs; national programs were identified in Norway [83-86], the UK [95], and Canada $[91,97]$. Fruits and vegetables were the most common dietary targets; other targets included low-fat snacks, milk, whole grain products, and water. Interventions that aimed to increase fruit and vegetable intake appeared effective. For example, the Norwegian School Fruit Program [85] that provided one piece of fruit or carrot per student on each school day increased fruit and vegetable school intake by 0.8 servings/day after 9 months. Similarly, a local school program that distributed free fruits and vegetables for 8 months increased total fruit intake by 0.55 servings/day [90].

Twenty-six interventions evaluated the effect of restricting unhealthful foods and beverages in schools $[92,99,101$, 114-131], with average duration of follow-up of 2 years. School settings include cafeterias, vending machines, and other competitive foods such as at school stores, snack bars, or snack trucks. Types of policies included restrictions or bans, nutrient standards for competitive foods, and combinations of these approaches. About half were local programs; others were based on city, state, or national policies. Overall, the interventions appeared generally effective in reducing intake of unhealthful competitive foods and beverages and decreasing incidence and prevalence of overweight/obesity. Governmental and school policies appeared more effective compared to voluntary programs. For example, the Boston Public Schools Snack and Beverage Policy that restricted SSBs at vending and a la carte settings found a 0.3 servings/ day reduction in total daily SSB intake by students at 18 months, compared to no change in national trends during this same time period [122]. In the HEALTH study, a randomized controlled trial conducted in 42 schools across five US states, a SSB ban, and limits on milk fat content and energy content of food served throughout the school environment decreased obesity prevalence by $19 \%$ at 3 years [132]. In the randomized controlled School Nutrition Policy Initiative in 10 US schools, an intervention that banned SSBs and restricted milk fat content and sugar and total/saturated fat content of snacks sold throughout the school environment reduced overweight incidence by $50 \%$ and overweight prevalence by $35 \%$ after 2 years [116].

Twenty-two interventions assessed standards for school meals for lunch and/or breakfast [97, 125, 129, 132-155], with average follow-up of 18-24 months. Standards were typically based on both types of foods (e.g., fried potatoes) and nutrient content (e.g., total fat, saturated fat, sodium) or portion size (e.g., portion of milk). Nine of these studies were randomized trials at the local level [129, 132, 134, 136, 139, 141-143, 145-148, 153, 155], while 13 were quasiexperimental studies of governmental policies (e.g., national food-based standards for school lunches in the UK and Texas [97, 125, 140, 149-151], the US Child Nutrition and WIC Reauthorization Act [133, 154], and other programs [135, 137, 138, 144, 152]). About one third of studies combined school meal standards with food and nutrient standards for competitive foods and beverages. About half also had nondietary targets, most commonly education or strategies to increase physical activity. 
Dietary targets varied appreciably; most common were total fat, saturated fat, sodium, fruits, vegetables, whole grains, SSBs, milk, and sweets. For example, the HEALTHY study aimed to lower the fat content of foods served; provide 1 serving of fruits and/or vegetables at breakfast and $2+$ at lunch; limit calories of dessert and snack foods to up to $200 \mathrm{kcal}$ per item; limit beverages to water, $1 \%$ or skim milk, and $100 \%$ fruit juice ( $6 \mathrm{oz}$ limit, only at breakfast or as an after-school snack); and provide 1 serving of fiber-rich grainbased food at breakfast and 2+ at lunch [132, 139, 148].

Overall, results were inconsistent across studies of school meal standards, with some but not others demonstrating intended changes in diet or diet-related risk factors (e.g., $\mathrm{BMI})$. For example, one national regulation with food and nutrient/portion size standards found a decrease in student BMI [133], while other similar programs did not [97, 132, 134, 138, 153]. The relevance of the primary dietary targets in these analyses may influence efficacy; for example, focusing on total fat or other single nutrient targets may have little impact. No consistent patterns were identified to explain the heterogeneous findings, e.g., according to type of policy, dietary target, setting, etc. In sum, changes in school procurement policies appear effective for either increasing healthful or reducing unhealthful choices, while setting of nutrition standards have less consistent benefits.

\section{Worksite Wellness Programs}

Most adults spend much of their weekday at work, making it a natural setting for health promotion strategies. Worksite wellness interventions typically focus on improving health, reducing insurance costs, and increasing productivity. Programs have used a variety of mechanisms to promote health and can be directed toward the entire workforce or high-risk individuals.

Prior reviews have concluded that multicomponent worksite wellness programs targeting diet, physical activity, and tobacco appear effective for improving employee health [9••]. We reviewed these prior reports as well as more recent interventional studies targeted toward the general employee population that included an external control group and evaluated changes in diet, adiposity, or CVD risk factors. Durations of interventions were highly variable, ranging from weeks to several years. Typical components included employee steering committees; group education classes; promotional and educational materials such as newsletters, signs, and brochures; health risk assessments; weight loss competitions; group exercise classes; signs to promote stair use; and cafeteria changes such as increased availability of healthy foods and nutrition labeling.

We found that several, although not all [156-164], worksite programs improved employees' diets, especially fruit and vegetable intake [165-168], and reduced adiposity [169-172]. For example, a 2-year multicomponent worksite intervention increased fruit and vegetable consumption by 0.3 servings/day, which was maintained for 2 years post-intervention [166]. A 2year worksite intervention among teachers resulted in $3 \mathrm{lb}$ weight loss [169]. Other recent systematic reviews found evidence that worksite wellness interventions reduce body weight [173] and increase fruit and vegetable intake [174].

In sum, comprehensive worksite wellness interventions appear effective at improving diet and diet-related risk factors. Yet, while worksite wellness programs have been tested with controlled interventions, certain methodologic challenges limit strong inference from some of these studies. These include heterogeneous intervention strategies, small sample sizes, short durations of follow-up, incomplete quality of reporting, moderate loss to follow-up, and low participation rates. Future research should be directed toward optimizing targets of interventions (e.g., food-based healthful diet patterns [175]), understanding optimal intervention components and their interactions (e.g., peer support, competitions, environmental change, mobile device feedback), increasing employer and employee participation and retention, increasing duration of interventions and follow-up, and evaluating programs in low- and middle-income nations.

\section{Marketing Restrictions and Quality Standards}

Based on the recognized power of marketing and billions of dollars spent by industry, implementing quality standards or restrictions on advertising of foods to youth is widely considered an effective strategy to improve diet [9••, 176, 177]. US children aged 2-5 and 6-11 years are estimated to view 10.9 and 12.7 food-related television advertisements each day, respectively, most often for foods and beverages of limited nutritional value [178]. Yet, despite compelling evidence that marketing of less healthful foods/beverages to children is common and associated with preferences and purchase requests, there is little data quantifying the impact of marketing standards or restrictions on long-term dietary intakes or health endpoints. In a longitudinal study of US children, based on indirect assessment of exposure to local fast food advertising, a theoretical complete ban was estimated to reduce the prevalence of childhood overweight by 18 and $14 \%$ among 3-11 and 12-18-year-olds, respectively [179]. These single estimates, without reported measures of precision, led to suggestions that food advertising bans are a highly cost-effective approach to reducing global chronic disease [180]. While there is little doubt that marketing impacts dietary preferences and purchase requests and while other experiences (e.g., tobacco control) strongly support benefits of marketing standards or restrictions, evidence to determine potential magnitudes of benefit for diet and adiposity remain elusive.

From legal and constitutional perspectives, placement of quality standards or restrictions on food marketing to children is supported by evidence that such advertising is deceptive, as children are unable to differentiate marketing/advertisements from content programming [177], although this theory has not 
been tested in US court [181]. Several countries, including Greece, Sweden, Belgium, UK, Ireland, and Quebec, have either restricted or set quality standards on how foods are marketed to children [182]. Evidence on the impact of such policies remains sparse. In the UK, statutory scheduling restrictions on the times of marketing to children of foods high in fat, sugar, or salt were more than offset by increased advertising of these products in other hours, so that overall exposure to such marketing did not change in children and substantially increased in adults [183].

In efforts to limit external regulation, industry consortia such as the Children's Food and Beverage Advertising Initiative, spearheaded by the US Council of Better Business Bureaus and many food manufacturers/restaurants, have voluntarily committed to not advertise or only advertise approved foods to children younger than 12 years [182, 184, 185]. However, the nutrition standards of this industry-supported program have been critiqued as being lax [186]. In addition, many major food companies are not participating, and children still have relatively high levels of advertising exposure on programs aimed at adolescents and adults [183, 187].

Based on broad observations, it is evident that marketing influences food choices in both children and adults. Quality standards or restrictions on such marketing present a promising strategy for improving population choices; more studies are needed on outcomes in countries implementing such approaches. Also, as the nature of advertising has shifted from television and other traditional media toward mobile, internet, program placement, and game-based marketing, additional research is needed to evaluate the impact of quality standards on these approaches. In addition, there is little data on exposure to marketing and policy standards in low- and middleincome countries, a crucial area for future research.

\section{Conclusions}

Our review supports the effectiveness of specific policy strategies to improve diet. These include focused mass media campaigns (especially to increase fruits and vegetables and to reduce salt), food pricing strategies (including both subsidies and taxation, with stronger effects at lower income levels), school procurement policies (to either increase healthful or reduce unhealthful choices), and worksite wellness programs (especially when such programs are comprehensive and multicomponent).

Evidence was mixed and inconclusive for efficacy of food and menu labeling (on either consumer or industry behavior), changes in the local built environment (e.g., availability or accessibility of supermarkets, fast food outlets, etc.), and implementation of nutrition standards for school meals (e.g., for school lunch or breakfast). We found little empiric evidence to evaluate effects of marketing restrictions, although broad principles and large resources spent on marketing suggest that this is a promising area for application and assessment.

Suboptimal dietary habits are now the leading cause of poor health in the USA and globally $[1,2]$.

Widespread implementation and evaluation of evidencebased policy strategies, as well as further research on other strategies with mixed or limited evidence, are essential approaches to "population medicine" to reduce the health and economic burdens of diet-related illness worldwide.

\section{Compliance with Ethics Guidelines}

Conflict of Interest Ashkan Afshin, Jose Penalvo, Liana Del Gobbo, Michael Kashaf, Renata Micha, Kurtis Morrish, Jonathan PearsonStuttard, Colin Rehm, Siyi Shangguan, Jessica D. Smith, and Dariush Mozaffarian declare that they have no conflict of interest.

Human and Animal Rights and Informed Consent This article does not contain any studies with human or animal subjects performed by any of the authors.

Open Access This article is distributed under the terms of the Creative Commons Attribution 4.0 International License (http:// creativecommons.org/licenses/by/4.0/), which permits unrestricted use, distribution, and reproduction in any medium, provided you give appropriate credit to the original author(s) and the source, provide a link to the Creative Commons license, and indicate if changes were made.

\section{References}

Papers of particular interest, published recently, have been highlighted as:

- Of importance

•. Of major importance

1. Lim SS, Vos T, Flaxman AD, et al. A comparative risk assessment of burden of disease and injury attributable to 67 risk factors and risk factor clusters in 21 regions, 1990-2010: a systematic analysis for the Global Burden of Disease Study 2010. Lancet. 2013;380: 2224-60.

2. US Burden of Disease Collaborators. The state of US health, 1990-2010: burden of diseases, injuries, and risk factors. JAMA. 2013;310:591-608.

3. Micha R, Khatibzadeh S, Shi P, et al. Global, regional, and national consumption levels of dietary fats and oils in 1990 and 2010: a systematic analysis including 266 country-specific nutrition surveys. BMJ (Clinical research ed). 2014;348:g2272.

4. Singh GM, Micha R, Khatibzadeh S et al. Global, regional, and national consumption levels of sugar-sweetened beverages, fruit juice, and milk: a systematic analysis including 195 countryspecific nutrition surveys worldwide. PLoS One 2015:in press.

5. Powles J, Fahimi S, Micha R, et al. Global, regional and national sodium intakes in 1990 and 2010: a systematic analysis of $24 \mathrm{~h}$ urinary sodium excretion and dietary surveys worldwide. BMJ open. 2013;3:e003733.

6. Mozaffarian D. Chapter 46. Nutrition and Cardiovascular Disease and Metabolic Diseases. In: Mann DL, Zipes DP, Libby P, Bonow RO, editors. Braunwald's Heart Disease; A Textbook of 
Cardiovascular Medicine, 10th Edition. Philadelphia: Elsevier/ Saunders, 2014.

7. Artinian NT, Fletcher GF, Mozaffarian D, et al. Interventions to promote physical activity and dietary lifestyle changes for cardiovascular risk factor reduction in adults: a scientific statement from the American Heart Association. Circulation. 2010;122:406-41.

8. Spring B, Ockene JK, Gidding SS, et al. Better population health through behavior change in adults: a call to action. Circulation. 2013;128:2169-76

9.• Mozaffarian D, Afshin A, Benowitz NL, et al. Population approaches to improve diet, physical activity, and smoking habits: a Scientific Statement from the American Heart Association. Circulation. 2012;126:1514-63. This study systematically reviewed, synthesized, and graded scientific evidence (published until February 2011) on effectiveness of various policy strategies to improve diet, physical activity, and smoking.

10. Afshin A, Micha R, Khatibzadeh S, Schmidt L, Mozaffarian D. Dietary policies to reduce noncommunicable diseases. In: Brown G, Yamey G, Wamala S, editors. The handbook of global health policy. San Francisco: Wiley-Blackwell; 2014.

11. Connell D, Goldberg JP, Folta SC. An intervention to increase fruit and vegetable consumption using audio communications: in-store public service announcements and audiotapes. J Health Commun. 2001;6:31-43.

12. Croft JB, Temple SP, Lankenau B, et al. Community intervention and trends in dietary fat consumption among black and white adults. J Am Diet Assoc. 1994;94:1284-90.

13. Agriculture UDo. Economic Research Service. 1999.

14. Farquhar JW, Fortmann SP, Flora JA, et al. Effects of communitywide education on cardiovascular disease risk factors. The Stanford Five-City Project. JAMA. 1990;264:359-65.

15. Mead EL, Gittelsohn J, Roache C, Corriveau A, Sharma S. A community-based, environmental chronic disease prevention intervention to improve healthy eating psychosocial factors and behaviors in indigenous populations in the Canadian Arctic. Health Educ Behav Off Publ Soc Public Health Educ. 2013;40:592-602.

16. Nguyen QN, Pham ST, Nguyen VL, et al. Effectiveness of community-based comprehensive healthy lifestyle promotion on cardiovascular disease risk factors in a rural Vietnamese population: a quasi-experimental study. BMC Cardiovasc Disord. 2012;12:56.

17. Reger B, Wootan MG, Booth-Butterfield S, Smith H. $1 \%$ or less: a community-based nutrition campaign. Public health reports (Washington, DC : 1974) 1998;113:410-9.

18. Bhalla V, Fong CW, Chew SK, Satku K. Changes in the levels of major cardiovascular risk factors in the multi-ethnic population in Singapore after 12 years of a national non-communicable disease intervention programme. Singap Med J. 2006;47:841-50.

19. Croker H, Lucas R, Wardle J. Cluster-randomised trial to evaluate the 'Change for Life' mass media/ social marketing campaign in the UK. BMC Public Health. 2012;12:404.

20. Dowse GK, Gareeboo H, Alberti KG, et al. Changes in population cholesterol concentrations and other cardiovascular risk factor levels after five years of the non-communicable disease intervention programme in Mauritius Mauritius Non-communicable Disease Study Group. BMJ (Clinical research ed). 1995;311:1255-9.

21. Keyte J, Harris S, Margetts B, Robinson S, Baird J. Engagement with the National Healthy Schools Programme is associated with higher fruit and vegetable consumption in primary school children. J Hum Nutr Diet Off J Br Diet Assoc. 2012;25:155-60.

22. Pekka P, Pirjo P, Ulla U. Influencing public nutrition for noncommunicable disease prevention: from community intervention to national programme - experiences from Finland. Public Health Nutr. 2002;5:245-51.

23. Puska P, Stahl T. Health in all policies-the Finnish initiative: background, principles, and current issues. Annu Rev Public Health. 2010;31:315-28. 3 p following 328.
24. Sanigorski AM, Bell AC, Kremer PJ, Cuttler R, Swinburn BA. Reducing unhealthy weight gain in children through community capacity-building: results of a quasi-experimental intervention program, Be Active Eat Well. Int J Obes (Lond). 2008;32:1060-7.

25. Dixon H, Borland R, Segan C, Stafford H, Sindall C. Public reaction to Victoria's "2 Fruit 'n' 5 Veg Every Day" campaign and reported consumption of fruit and vegetables. Prev Med. 1998;27:572-82.

26. Erinosho TO, Moser RP, Oh AY, Nebeling LC, Yaroch AL. Awareness of the Fruits and Veggies-More Matters campaign, knowledge of the fruit and vegetable recommendation, and fruit and vegetable intake of adults in the 2007 Food Attitudes and Behaviors (FAB) Survey. Appetite. 2012;59:155-60.

27. Nishtar S, Mirza YA, Jehan S, et al. Newspaper articles as a tool for cardiovascular prevention programs in a developing country. $\mathrm{J}$ Health Commun. 2004;9:355-69.

28. Lutz SF, Ammerman AS, Atwood JR, Campbell MK, DeVellis $\mathrm{RF}$, Rosamond WD. Innovative newsletter interventions improve fruit and vegetable consumption in healthy adults. J Am Diet Assoc. 1999;99:705-9.

29. Afshin A, Abioye AI, Ajala ON, Nguyen AB, See KC, Mozaffarian D. Abstract P087: Effectiveness of Mass Media Campaigns for Improving Dietary Behaviors: A Systematic Review and Meta-analysis. Circulation 2013;127:AP087.

30. Sutherland J, Edwards P, Shankar B, Dangour AD. Fewer adults add salt at the table after initiation of a national salt campaign in the UK: a repeated cross-sectional analysis. Br J Nutr. 2013;110: 552-8.

31. Stables GJ, Subar AF, Patterson BH, et al. Changes in vegetable and fruit consumption and awareness among US adults: results of the 1991 and 19975 A Day for Better Health Program surveys. J Am Diet Assoc. 2002;102:809-17.

32. Livsmedelsverket. The Keyhole. Food and Content - Labelling, 2015.

33. Dotsch-Klerk M, Jansen L. The Choices programme: a simple, front-of-pack stamp making healthy choices easy. Asia Pac J Clin Nutr. 2008;17 Suppl 1:383-6.

34. Association AH. Heart-Check Food Certification Program Nutrition Requirements. Nutrition Center.

35. Sally Malam SC, Sarah K, Stephen MG. BMRB Social Research. Comprehension and use of UK nutrition signpost labelling schemes. London: Food Standards Agency; 2009.

36. Agency FS. Signposting and traffic light labelling. Ireland: FSA in Northern; 2010.

37. Sutherland LA, Kaley LA, Fischer L. Guiding Stars: the effect of a nutrition navigation program on consumer purchases at the supermarket. Am J Clin Nutr. 2010;91:1090S-4S.

38. Bernell B. The history and impact of the New York City menu labeling law. Food and Drug Law Journal. 2010;65:unpaginated.

39. Swartz JJ, Braxton D, Viera AJ. Calorie menu labeling on quickservice restaurant menus: an updated systematic review of the literature. International Journal of Behavioral Nutrition and Physical Activity 2011;8:(8 December 2011).

40. Finkelstein EA, Strombotne KL, Chan NL, Krieger J. Mandatory menu labeling in one fast-food chain in King County, Washington. Am J Prev Med. 2011;40:122-7.

41. Elbel B, Gyamfi J, Kersh R. Child and adolescent fast-food choice and the influence of calorie labeling: a natural experiment. Int J Obes (Lond). 2011;35:493-500.

42. Tandon PS, Zhou C, Chan NL, et al. The impact of menu labeling on fast-food purchases for children and parents. Am J Prev Med. 2011;41:434-8.

43. Krieger JW, Chan NL, Saelens BE, Ta ML, Solet D, Fleming DW. Menu labeling regulations and calories purchased at chain restaurants. Am J Prev Med. 2013;44:595-604. 
44. Hammond D, Goodman S, Hanning R, Daniel S. A randomized trial of calorie labeling on menus. Prev Med. 2013;57:860-6.

45. Harnack LJ, French SA, Oakes JM, Story MT, Jeffery RW, Rydell SA. Effects of calorie labeling and value size pricing on fast food meal choices: results from an experimental trial. International Journal of Behavioral Nutrition and Physical Activity 2008;5:(5 December 2008).

46. Liu PJ, Roberto CA, Liu LJ, Brownell KD. A test of different menu labeling presentations. Appetite. 2012;59:770-7.

47. Lowe MR, Tappe KA, Butryn ML, et al. An intervention study targeting energy and nutrient intake in worksite cafeterias. Eat Behav. 2010;11:144-51.

48. Vanderlee L, Hammond D. Does nutrition information on menus impact food choice? Comparisons across two hospital cafeterias. Public Health Nutr 2013:1-11.

49. Gerend MA. Does calorie information promote lower calorie fast food choices among college students? J Adolesc Health. 2009;44: 84-6.

50. Steenhuis IHM, Kroeze W, Vyth EL, Valk S, Verbauwen R, Seidell JC. The effects of using a nutrition logo on consumption and product evaluation of a sweet pastry. Appetite. 2010;55:7079.

51. Steenhuis I, Van Assema P, Van Breukelen G, Glanz K, Kok G, De Vries $\mathrm{H}$. The impact of educational and environmental interventions in Dutch worksite cafeterias. Health Promot Int. 2004;19: 335-43.

52. Temple JL, Johnson KM, Archer K, LaCarte A, Yi C, Epstein LH. Influence of simplified nutrition labeling and taxation on laboratory energy intake in adults. Appetite. 2011;56:184-92.

53. Roberto CA, Larsen PD, Agnew H, Baik J, Brownell KD. Evaluating the impact of menu labeling on food choices and intake. Am J Public Health. 2010;100:312-8

54. Thorndike AN, Riis J, Sonnenberg LM, Levy DE. Traffic-light labels and choice architecture: promoting healthy food choices. Am J Prev Med. 2014;46:143-9.

55. Friesen R, Innis SM. Trans fatty acids in human milk in Canada declined with the introduction of trans fat food labeling. J Nutr. 2006;136:2558-61.

56. Shangguan S, Smith J, Ma W, Tanz L, Afshin A, Mozaffarian D. Effectiveness of point-of-purchase labeling on dietary behaviors and nutrient contents of foods: a systemic review and metaanalysis (abstract). Circulation. 2015;131:AP323.

57. Rothman RL, Housam R, Weiss H, et al. Patient understanding of food labels: the role of literacy and numeracy. Am J Prev Med. 2006;31:391-8

58. Auchincloss AH, Young C, Davis AL, Wasson S, Chilton M, Karamanian V. Barriers and facilitators of consumer use of nutrition labels at sit-down restaurant chains. Public Health Nutr. 2013;16:2138-45.

59. Weinehall L, Hellsten G, Boman K, Hallmans G. Prevention of cardiovascular disease in Sweden: the Norsjö community intervention programme - motives, methods and intervention components. Scandinavian Journal of Public Health. 2001:13-20.

60. Giesen JC, Payne CR, Havermans RC, Jansen A. Exploring how calorie information and taxes on high-calorie foods influence lunch decisions. Am J Clin Nutr. 2011;93:689-94.

61. Waterlander WE, Steenhuis IH, de Boer MR, Schuit AJ, Seidell JC. Effects of different discount levels on healthy products coupled with a healthy choice label, special offer label or both: results from a web-based supermarket experiment. Int J Behav Nutr Phys Act. 2013;10:59.

62. Namba A, Auchincloss A, Leonberg BL, Wootan MG. Exploratory analysis of fast-food chain restaurant menus before and after implementation of local calorie-labeling policies, 20052011. Prev Chronic Dis. 2013;10:E101.
63. Wu HW, Sturm R. Changes in the energy and sodium content of main entrees in US chain restaurants from 2010 to 2011. J Acad Nutr Diet. 2014;114:209-19.

64. Vyth EL, Steenhuis IH, Roodenburg AJ, Brug J, Seidell JC. Frontof-pack nutrition label stimulates healthier product development: a quantitative analysis. Int J Behav Nutr Phys Act. 2010;7:65.

65. Van Camp D, Hooker NH, Lin CT. Changes in fat contents of US snack foods in response to mandatory trans fat labelling. Public Health Nutr. 2012;15:1130-7.

66. Afshin A, Micha R, Khatibzadeh S, Schmidt LA, Mozaffarian D. Dietary policies to reduce non-communicable diseases. In: Brown GW, Yamey G, Wamala S, editors. The Handbook of Global Health Policy. 1st ed. West Sussex: John Wiley \& Sons, Ltd.; 2014.

67. Powell LM, Chriqui JF, Khan T, Wada R, Chaloupka FJ. Assessing the potential effectiveness of food and beverage taxes and subsidies for improving public health: a systematic review of prices, demand and body weight outcomes. Obes Rev. 2013;14: 110-28.

68. Andreyeva T, Long MW, Brownell KD. The impact of food prices on consumption: a systematic review of research on the price elasticity of demand for food. Am J Public Health. 2010;100: 216-22.

69. Green R, Cornelsen L, Dangour AD, et al. The effect of rising food prices on food consumption: systematic review with meta-regression. BMJ (Clinical research ed). 2013;346:f3703. This study systematically evaluated and quantified the price-elasticity of demand for major food groups across 162 countries and examined changes in price-responsiveness by income at the country and household levels.

70. An R. Effectiveness of subsidies in promoting healthy food purchases and consumption: a review of field experiments. Public Health Nutr. 2013;16:1215-28.

71. Boone-Heinonen J, Gordon-Larsen P, Kiefe CI, Shikany JM, Lewis CE, Popkin BM. Fast food restaurants and food stores: longitudinal associations with diet in young to middle-aged adults: the CARDIA study. Arch Intern Med. 2011;171:1162-70.

72. Li F, Harmer P, Cardinal BJ, et al. Built environment and 1-year change in weight and waist circumference in middle-aged and older adults: Portland Neighborhood Environment and Health Study. Am J Epidemiol. 2009;169:401-8.

73. Block JP, Christakis NA, O'Malley AJ, Subramanian SV. Proximity to food establishments and body mass index in the Framingham Heart Study offspring cohort over 30 years. Am J Epidemiol. 2011;174:1108-14.

74. Boone-Heinonen J, Diez-Roux AV, Goff DC, et al. The neighborhood energy balance equation: does neighborhood food retail environment + physical activity environment $=$ obesity? The CARDIA study. PLoS One. 2013;8:e85141.

75. Gibson DM. The neighborhood food environment and adult weight status: estimates from longitudinal data. Am J Public Health. 2011;101:71-8.

76. Powell LM, Bao Y. Food prices, access to food outlets and child weight. Econ Hum Biol. 2009;7:64-72.

77. Shier V, An R, Sturm R. Is there a robust relationship between neighbourhood food environment and childhood obesity in the USA? Public Health. 2012;126:723-30.

78. Wang R, Shi L. Access to food outlets and children's nutritional intake in urban China: a difference-in-difference analysis. Ital J Pediatr. 2012;38:30.

79. Smith D, Cummins S, Clark C, Stansfeld S. Does the local food environment around schools affect diet? Longitudinal associations in adolescents attending secondary schools in East London. BMC Public Health. 2013;13:70.

80. Anderson AS, Porteous LE, Foster E, et al. The impact of a school-based nutrition education intervention on dietary intake 
and cognitive and attitudinal variables relating to fruits and vegetables. Public Health Nutr. 2005;8:650-6.

81. Ashfield-Watt PA, Stewart EA, Scheffer JA. A pilot study of the effect of providing daily free fruit to primary-school children in Auckland, New Zealand. Public Health Nutr. 2009:693-701.

82. Bartholomew JB, Jowers EM. Increasing frequency of lower-fat entrees offered at school lunch: an environmental change strategy to increase healthful selections. J Am Diet Assoc. 2006:248-52.

83. Bere E, Veierod MB, Klepp KI. The Norwegian School Fruit Programme: evaluating paid vs. no-cost subscriptions. Prev Med. 2005;41:463-70.

84. Bere E, Veierød MB, Bjelland M, Klepp KI. Free school fruitsustained effect 1 year later. Health education research. 2006:26875

85. Bere E, Veierod MB, Skare O, Klepp KI. Free School Fruitsustained effect three years later. Int J Behav Nutr Phys Act. 2007;4:5

86. Bere E, Hilsen M, Klepp KI. Effect of the nationwide free school fruit scheme in Norway. Br J Nutr, 2010:589-94.

87. Bonsergent E, Agrinier N, Thilly N, et al. Overweight and obesity prevention for adolescents: a cluster randomized controlled trial in a school setting. Am J Prev Med. 2013;44:30-9.

88. Burgess-Champoux TL, Chan HW, Rosen R, Marquart L, Reicks $\mathrm{M}$. Healthy whole-grain choices for children and parents: a multicomponent school-based pilot intervention. Public Health Nutr. 2008;11:849-59.

89. Coleman KJ, Shordon M, Caparosa SL, Pomichowski ME, Dzewaltowski DA. The healthy options for nutrition environments in schools (Healthy ONES) group randomized trial: using implementation models to change nutrition policy and environments in low income schools. The international journal of behavioral nutrition and physical activity. 2012:80.

90. Coyle KK, Potter S, Schneider D, et al. Distributing free fresh fruit and vegetables at school: results of a pilot outcome evaluation. Public Health Rep. 2009;124:660-9.

91. Davis EM, Cullen KW, Watson KB, Konarik M, Radcliffe J. A Fresh Fruit and Vegetable Program improves high school students' consumption of fresh produce. J Am Diet Assoc. 2009;109:122731.

92. Eagle TF, Gurm R, Smith CA, et al. A middle school intervention to improve health behaviors and reduce cardiac risk factors. Am J Med. 2013;126:903-8.

93. Eriksen K, Haraldsdottir J, Pederson R, Flyger HV. Effect of a fruit and vegetable subscription in Danish schools. Public Health Nutr. 2003;6:57-63.

94. Fiske A, Cullen KW. Effects of promotional materials on vending sales of low-fat items in teachers' lounges. Journal of the American Dietetic Association. 2004:90-3.

95. Fogarty AW, Antoniak M, Venn AJ, et al. Does participation in a population-based dietary intervention scheme have a lasting impact on fruit intake in young children? Int J Epidemiol. 2007;36: 1080-5.

96. French SA, Story M, Fulkerson JA, Hannan P. An environmental intervention to promote lower-fat food choices in secondary schools: outcomes of the TACOS Study. American journal of public health, 2004:1507-12.

97. Fung C, McIsaac JLD, Kuhle S, Kirk SFL, Veugelers PJ. The impact of a population-level school food and nutrition policy on dietary intake and body weights of Canadian children. Prev Med 2013.

98. He M, Beynon C, Sangster Bouck M et al. Impact evaluation of the Northern Fruit and Vegetable Pilot Programme - a clusterrandomised controlled trial. Public Health Nutr, 2009:2199-208.

99. Hoppu U, Lehtisalo J, Kujala J, et al. The diet of adolescents can be improved by school intervention. Public Health Nutr. 2010;13: 973-9.
100. Kim KR. Hanyang University, Seoul, Republic of Korea, Hong SA, Hanyang University, Seoul, Republic of Korea, Yun SH, Hanyang University, Seoul, Republic of Korea, Ryou HJ, Health Promotion Division, Seoul Metropolitan Government, Seoul, Republic of Korea, Lee SS, Hanyang University, Seoul, Republic of Korea, Kim MK, Hanyang University, Seoul, Republic of Korea. Effect Health Sch Tuck Shop Prog Access stud Health Foods. 2012;6(2):138-45.

101. Kocken PL, Eeuwijk J, Van Kesteren NM, et al. Promoting the purchase of low-calorie foods from school vending machines: a cluster-randomized controlled study. J Sch Health. 2012;82:11522.

102. Loughridge JL, Barratt J. Does the provision of cooled filtered water in secondary school cafeterias increase water drinking and decrease the purchase of soft drinks? Journal of human nutrition and dietetics : the official journal of the British Dietetic Association. 2005:281-6.

103. Lytle LA, Murray DM, Perry CL, et al. School-based approaches to affect adolescents' diets: results from the TEENS study. Health Educ Behav Off Publ Soc Public Health Educ. 2004;31:270-87.

104. Moore L, Tapper K. The impact of school fruit tuck shops and school food policies on children's fruit consumption: a cluster randomised trial of schools in deprived areas. Journal of epidemiology and community health. 2008:926-31.

105. Muckelbauer R, Libuda L, Clausen K, Toschke AM, Reinehr T, Kersting M. Promotion and provision of drinking water in schools for overweight prevention: randomized, controlled cluster trial. Pediatrics, 2009:e661-7.

106. Perry CL, Bishop DB, Taylor GL et al. A randomized school trial of environmental strategies to encourage fruit and vegetable consumption among children. Health education \& behavior : the official publication of the Society for Public Health Education. 2004: 65-76.

107. Rahmani K, Djazayery A, Habibi MI, et al. Effects of daily milk supplementation on improving the physical and mental function as well as school performance among children: results from a school feeding program. J Res Med Sci Off J Isfahan University Med Sci. 2011;16:469-76.

108. Ransley JK, Greenwood DC, Cade JE, et al. Does the school fruit and vegetable scheme improve children's diet? A non-randomised controlled trial. J Epidemiol Community Health. 2007;61:699703.

109. Reinaerts E, Crutzen R, Candel M, Vries NK, Nooijer J. Increasing fruit and vegetable intake among children: comparing long-term effects of a free distribution and a multicomponent program. Health education research. 2008:987-96.

110. Slusser WM, Cumberland WG, Browdy BL, Lange L, Neumann C. A school salad bar increases frequency of fruit and vegetable consumption among children living in low-income households. Public Health Nutr. 2007;10:1490-6.

111. Tak NI, Te Velde SJ, Brug J. Long-term effects of the Dutch Schoolgruiten Project-promoting fruit and vegetable consumption among primary-school children. Public Health Nutr. 2009;12: 1213-23.

112. te Velde SJ, Brug J, Wind M, et al. Effects of a comprehensive fruit- and vegetable-promoting school-based intervention in three European countries: the Pro Children Study. Br J Nutr. 2008;99: 893-903.

113. Whitaker RC, Wright JA, Finch AJ, Psaty BM. An environmental intervention to reduce dietary fat in school lunches. Pediatrics. 1993;91:1107-11.

114. Bae SG, Kim JY, Kim KY, Park SW, Bae J, Lee WK. Changes in dietary behavior among adolescents and their association with government nutrition policies in Korea, 2005-2009. J Prev Med Public Health. 2012;45:47-59. 
115. Bauhoff S. The effect of school district nutrition policies on dietary intake and overweight: a synthetic control approach. Econ Hum Biol. 2014;12:45-55.

116. Foster GD, Sherman S, Borradaile KE, et al. A policy-based school intervention to prevent overweight and obesity. Pediatrics. 2008;121:e794-802.

117. Kim K, Hong SA, Yun SH, Ryou HJ, Lee SS, Kim MK. The effect of a healthy school tuck shop program on the access of students to healthy foods. Nutr Res Pract. 2012;6:138-45.

118. Long MW, Henderson KE, Schwartz MB. Evaluating the impact of a Connecticut program to reduce availability of unhealthy competitive food in schools. J Sch Health. 2010;80:478-86.

119. Moore L, Tapper K. The impact of school fruit tuck shops and school food policies on children's fruit consumption: a cluster randomised trial of schools in deprived areas. J Epidemiol Community Health. 2008;62:926-31.

120. Woodward-Lopez G, Gosliner W, Samuels SE, Craypo L, Kao J, Crawford PB. Lessons learned from evaluations of California's statewide school nutrition standards. Am J Public Health. 2010;100:2137-45.

121. Coleman KJ, Shordon M, Caparosa SL, Pomichowski ME, Dzewaltowski DA. The healthy options for nutrition environments in schools (Healthy ONES) group randomized trial: using implementation models to change nutrition policy and environments in low income schools. Int J Behav Nutr Phys Act. 2012;9: 80.

122. Cradock AL, McHugh A, Mont-Ferguson H, et al. Effect of school district policy change on consumption of sugar-sweetened beverages among high school students, Boston, Massachusetts, 20042006. Prev Chronic Dis. 2011;8:A74.

123. Matthews A, Nelson M, Kaur A, Rayner M, Kelly P, Cowburn G. Where has all the chocolate gone? A national survey assesses the effects of recent legislation to improve the nutritional quality of English secondary-school vending. Public Health Nutr. 2011;14: $1394-402$.

124. Sanchez-Vaznaugh EV, Sánchez BN, Baek J, Crawford PB. 'Competitive' food and beverage policies: are they influencing childhood overweight trends? Health Aff. 2010;29:436-46.

125. Cullen KW, Watson K, Zakeri I. Improvements in middle school student dietary intake after implementation of the Texas Public School Nutrition Policy. Am J Public Health. 2008;98:111-7.

126. Taber DR, Chriqui JF, Chaloupka FJ. Differences in nutrient intake associated with state laws regarding fat, sugar, and caloric content of competitive foods. Arch Pediatr Adolesc Med. 2012;166:452-8.

127. Taber DR, Chriqui JF, Perna FM, Powell LM, Chaloupka FJ. Weight status among adolescents in States that govern competitive food nutrition content. Pediatrics. 2012;130:437-44

128. Blum JE, Davee AM, Beaudoin CM, Jenkins PL, Kaley LA, Wigand DA. Reduced availability of sugar-sweetened beverages and diet soda has a limited impact on beverage consumption patterns in Maine high school youth. J Nutr Educ Behav. 2008;40: 341-7.

129. Marcus C, Nyberg G, Nordenfelt A, Karpmyr M, Kowalski J, Ekelund U. A 4-year, cluster-randomized, controlled childhood obesity prevention study: STOPP. Int J Obes (Lond). 2009;33: $408-17$

130. Schwartz MB, Novak SA, Fiore SS. The impact of removing snacks of low nutritional value from middle schools. Health Educ Behav Off Publ Soc Public Health Educ. 2009;36:9991011.

131. Jensen CD, Sato AF, McMurtry CM, Hart CN, Jelalian E. School nutrition policy an evaluation of the rhode island healthier beverages policy in schools. ICAN: Infant Child Adolesc Nutr. 2012;4: $276-82$.
132. Foster GD, Linder B, Baranowski T, et al. A school-based intervention for diabetes risk reduction. N Engl J Med. 2010;363:44353.

133. Anderson LM, Aycock KE, Mihalic CA, Kozlowski DJ, Detschner AM. Geographic differences in physical education and adolescent BMI: have legal mandates made a difference? J Sch Nurs. 2013;29:52-60.

134. Ask AS, Hernes S, Aarek I, Vik F, Brodahl C, Haugen M. Serving of free school lunch to secondary-school pupils - a pilot study with health implications. Public Health Nutr. 2010:238-44.

135. Cohen JF, Smit LA, Parker E, et al. Long-term impact of a chef on school lunch consumption: findings from a 2-year pilot study in Boston middle schools. J Acad Nutr Diet. 2012;112:927-33.

136. Dwyer JT, Hewes LV, Mitchell PD, et al. Improving school breakfasts: effects of the CATCH Eat Smart Program on the nutrient content of school breakfasts. Prev Med. 1996;25:413-22.

137. Folta S, Kuder J, Goldberg J, et al. Changes in diet and physical activity resulting from the Shape Up Somerville community intervention. BMC Pediatr. 2013;13:157.

138. Hollar D, Lombardo M, Lopez-Mitnik G, et al. Effective multilevel, multi-sector, school-based obesity prevention programming improves weight, blood pressure, and academic performance, especially among low-income, minority children. J Health Care Poor Underserved. 2010;21:93-108.

139. Kaufman F, Hirst K, Buse J, et al. Effect of secular trends on a primary prevention trial: the HEALTHY study experience. Child Obes. 2011;7:291-7.

140. Long MW, Henderson KE, Schwartz MB. Evaluating the impact of a Connecticut program to reduce availability of unhealthy competitive food in schools. J Sch Health. 2010;80:478-86.

141. Murphy S, Moore GF, Tapper K et al. Free healthy breakfasts in primary schools: a cluster randomised controlled trial of a policy intervention in Wales, UK. Public Health Nutr. 2011:219-26.

142. Nicklas TATUSoPHaTM, New Orleans, LA.), Dwyer J, Yang M et al. The impact of modifying school meals on dietary intakes of school-aged children. (1996);v. 20(suppl.) p. 21-26.

143. Osganian SK, Hoelscher DM, Zive M, Mitchell PD, Snyder P, Webber LS. Maintenance of effects of the eat smart school food service program: results from the CATCH-ON study. Health Educ Behav Off Publ Soc Public Health Educ. 2003;30:418-33.

144. Simons-Morton BG, Parcel GS, Baranowski T, Forthofer R, O'Hara NM. Promoting physical activity and a healthful diet among children: results of a school-based intervention study. Am J Public Health. 1991;81:986-91.

145. Story M, Snyder MP, Anliker J, et al. Changes in the nutrient content of school lunches: results from the Pathways study. Prev Med. 2003;37:S35-45.

146. Cohen JF, Kraak VI, Choumenkovitch SF, Hyatt RR, Economos CD. The CHANGE study: a healthy-lifestyles intervention to improve rural children's diet quality. J Acad Nutr Diet. 2014;114:4853.

147. Luepker RV, Perry CL, McKinlay SM, et al. Outcomes of a field trial to improve children's dietary patterns and physical activity: the child and adolescent trial for cardiovascular health (catch). JAMA. 1996;275:768-76.

148. Group HS, Mobley CC, Stadler DD, et al. Effect of nutrition changes on foods selected by students in a middle school-based diabetes prevention intervention program: the HEALTHY experience. J Sch Health. 2012;82:82-90.

149. Haroun D, Harper C, Wood L, Nelson M. The impact of the foodbased and nutrient-based standards on lunchtime food and drink provision and consumption in primary schools in England. Public Health Nutr. 2011;14:209-18.

150. Mullally ML, Taylor JP, Kuhle S et al. A province-wide school nutrition policy and food consumption in elementary school 
children in Prince Edward Island. Canadian journal of public health=Revue canadienne de sante publique 2010;101:40-3.

151. Word Health Organization. Global status report on noncommunicable diseases 2010. Geneva, 2011.

152. Williams CL, Bollella MC, Strobino BA et al. "Healthy-start": outcome of an intervention to promote a heart healthy diet in preschool children. J Am Coll Nutr, 2002:62-71.

153. Williamson DA, Champagne CM, Harsha DW, et al. Effect of an environmental school-based obesity prevention program on changes in body fat and body weight: a randomized trial. Obesity (Silver Spring, Md). 2012;20:1653-61.

154. Spence S, Shen J, Delve J, White M, Vale L, Adamson AJ. An evaluation of the effect of the new school food policy on children's nutritional intake and socio-economic consequences in North East England. J Epidemiol Community Health. 2012;66:A32.

155. Williamson DA, Copeland AL, Anton SD, et al. Wise Mind project: a school-based environmental approach for preventing weight gain in children. Obesity. 2007;15:906-17.

156. Engbers LH, van Poppel MN, Chin APM, van Mechelen W. The effects of a controlled worksite environmental intervention on determinants of dietary behavior and self-reported fruit, vegetable and fat intake. BMC Public Health. 2006;6:253.

157. Gosliner WA, James P, Yancey AK, Ritchie L, Studer N, Crawford PB. Impact of a worksite wellness program on the nutrition and physical activity environment of child care centers. Am J Health Promot AJHP. 2010;24:186-9.

158. Jeffery RW, Forster JL, French SA, et al. The Healthy Worker Project: a work-site intervention for weight control and smoking cessation. Am J Public Health. 1993;83:395-401.

159. Glasgow RE, Terborg JR, Hollis JF, Severson HH, Boles SM. Take heart: results from the initial phase of a work-site wellness program. Am J Public Health. 1995;85:209-16.

160. DeJoy DM, Parker KM, Padilla HM, Wilson MG, Roemer EC, Goetzel RZ. Combining environmental and individual weight management interventions in a work setting: results from the Dow chemical study. J Occup Environ Med. 2011;53:245-52.

161. van Berkel J, Boot CR, Proper KI, Bongers PM, van der Beek AJ. Effectiveness of a worksite mindfulness-based multi-component intervention on lifestyle behaviors. Int J Behav Nutr Phys Act. 2014;11:9.

162. Lemon SC, Zapka J, Li W, et al. Step ahead a worksite obesity prevention trial among hospital employees. Am J Prev Med. 2010;38:27-38

163. French SA, Harnack LJ, Hannan PJ, Mitchell NR, Gerlach AF, Toomey TL. Worksite environment intervention to prevent obesity among metropolitan transit workers. Prev Med. 2010;50:180-5.

164. Linde JA, Nygaard KE, MacLehose RF, et al. HealthWorks: results of a multi-component group-randomized worksite environmental intervention trial for weight gain prevention. Int J Behav Nutr Phys Act. 2012;9:14.

165. Beresford SA, Thompson B, Feng Z, Christianson A, McLerran D, Patrick DL. Seattle 5 a day worksite program to increase fruit and vegetable consumption. Prev Med. 2001;32:230-8.

166. Beresford SA, Thompson B, Bishop S, Macintyre J, McLerran D, Yasui Y. Long-term fruit and vegetable change in worksites: Seattle 5 a day follow-up. Am J Health Behav. 2010;34:707-20.

167. Hutchinson AD, Howlett G, Wilson C. Increasing employees' fruit consumption through access and peer support at work. Food Nutr Sci. 2013;4:88-95.

168. Strijk JE, Proper KI, van der Beek AJ, van Mechelen W. A worksite vitality intervention to improve older workers' lifestyle and vitality-related outcomes: results of a randomised controlled trial. J Epidemiol Community Health. 2012;66:1071-8.

169. Lemon SC, Wang ML, Wedick NM, et al. Weight gain prevention in the school worksite setting: results of a multi-level cluster randomized trial. Prev Med. 2014;60:41-7.
170. Goetzel RZ, Roemer EC, Pei X, et al. Second-year results of an obesity prevention program at the Dow Chemical Company. J Occup Environ Med. 2010;52:291-302.

171. Kwak L, Kremers SP, Candel MJ, Visscher TL, Brug J, van Baak MA. Changes in skinfold thickness and waist circumference after 12 and 24 months resulting from the NHF-NRG In Balance-project. Int J Behav Nutr Phys Act. 2010;7:26.

172. Salinardi TC, Batra P, Roberts SB, et al. Lifestyle intervention reduces body weight and improves cardiometabolic risk factors in worksites. Am J Clin Nutr. 2013;97:667-76.

173. Gudzune K, Hutfless S, Maruthur N, Wilson R, Segal J. Strategies to prevent weight gain in workplace and college settings: a systematic review. Prev Med. 2013;57:268-77.

174. Geaney F, Kelly C, Greiner BA, Harrington JM, Perry IJ, Beirne P. The effectiveness of workplace dietary modification interventions: a systematic review. Prev Med. 2013;57:438-47.

175. Dietary Guidelines Advisory Committee. Scientific Report of the 2015 Dietary Guidelines Advisory Committee. US Department of Agriculture, Agriculutural Research Service. 2015.

176. World Health Organization. Set of recommendations on the marketing of foods and non-alcoholic beverages to children. Geneva, Switzerland, 2010

177. Institute of Medicine. Food Marketing to Children and Youth: Threat or Opportunity. Washington, DC: The National Academies Press; 2006.

178. Powell LM, Schermbeck RM, Szczypka G, Chaloupka FJ, Braunschweig CL. Trends in the nutritional content of television food advertisements seen by children in the United States: analyses by age, food categories, and companies. Arch Pediatr Adolesc Med. 2011;165:1078-86.

179. Chou S, Rashad I, Grossman M. Fast-food restaurant advertising on television and its influence on childhood obesity. J Law Econ. 2008;51:599-618.

180. Cecchini M, Sassi F, Lauer JA, Lee YY, Guajardo-Barron V, Chisholm D. Tackling of unhealthy diets, physical inactivity, and obesity: health effects and cost-effectiveness. Lancet. 2010;376: 1775-84.

181. Pomeranz JL. Television food marketing to children revisited: the Federal Trade Commission has the constitutional and statutory authority to regulate. J Law Med Ethics. 2010;38:98116.

182. Institute of Medicine. Challenges and opportunities for change in food marketing to children and youth: workshop summary. Washington, DC: The National Academies Press; 2013.

183. Adams J, Tyrrell R, Adamson AJ, White M. Effect of restrictions on television food advertising to children on exposure to advertisements for 'less healthy' foods: repeat cross-sectional study. PLoS One. 2012;7:e31578.

184. The Children's Food and Beverage Advertising Initiative. The children's food \& beverage advertising initiative in action: a report on compliance and progress during 2013. Arlington, Virginia: Council of Better Business Bureaus, 2014.

185. Children's Food \& Beverage Advertising Initiative. What "ChildDirected Advertising" means under CFBAI. Council of Better Business Bureaus, 2014.

186. Wootan M, Vickroy L, Pokress B. Putting nutrition in nutrition standards for marketing to kids: how marketed foods measure up in the interagency working group's proposed nutrition principles for food marketed to children. Washington, DC: Center for Science in the Public Interest; 2011.

187. Powell LM, Harris JL, Fox T. Food marketing expenditures aimed at youth: putting the numbers in context. Am J Prev Med. 2013;45:453-61. 